\title{
A randomized crossover study comparing trehalose/hyaluronate eyedrops and standard treatment: patient satisfaction in the treatment of dry eye syndrome
}

\author{
This article was published in the following Dove Press journal: \\ Therapeutics and Clinical Risk Management \\ 13 April 2015 \\ Number of times this article has been viewed
}

\author{
Juan Carlos Pinto-Bonilla' \\ Alberto del Olmo-Jimeno \\ Fernando Llovet-Osuna ${ }^{3}$ \\ Emiliano Hernández- \\ Galilea $^{4}$ \\ 'Department of Corneal, Refractive, \\ and Cataract Surgery, European \\ Ophthalmological Institute, Clínica \\ Baviera, Pamplona, Navarra, Spain; \\ ${ }^{2}$ Optometry Department, European \\ Ophthalmological Institute, Clínica \\ Baviera, Pamplona, Navarra, \\ Spain; ${ }^{3}$ Department of Refractive \\ and Cataract Surgery, European \\ Ophthalmological Institute, Clínica \\ Baviera, Madrid, Madrid, Spain; \\ ${ }^{4}$ Ophthalmology Department, \\ Hospital Clínico Universitario de \\ Salamanca, Universidad de Salamanca, \\ Salamanca, Salamanca, Spain
}

Correspondence: Juan Carlos Pinto-

Bonilla

Department of Corneal, Refractive, and Cataract Surgery, European

Ophthalmological Institute, Clínica

Baviera, Calle del Monasterio de

Vadoluengo 4, 31008 Pamplona,

Navarra, Spain

$\mathrm{Tel}+34948199615$

Fax +34948199883

Email jcpintobonilla@gmail.com

\begin{abstract}
Dry eye is a common disorder in routine ophthalmological practice, and a better understanding of the complex pathophysiology is leading to improved treatment. Thealoz Duo ${ }^{\circledR}$ is a novel artificial tear preparation containing two active ingredients: Trehalose, a naturally occurring disaccharide with anhydrobiotic functions in many organisms, and hyaluronate, a widely distributed anionic glycosaminoglycan polysaccharide with lubricative and waterretaining properties in biological systems. In a randomized, single center, open label, crossover study, 17 adult patients with moderate-to-severe dry eye syndrome were randomized to treatment with Thealoz Duo ${ }^{\circledR}$ (combining trehalose and hyaluronic acid) or Systane ${ }^{\circledR}$. Patients received 7 days of treatment. The primary efficacy variable was patient satisfaction evaluated by a 0-100 visual analog scale evaluated on days 0 and 7 of treatment. Secondary parameters included ocular surface disease index (OSDI), symptoms of dry eye, ocular staining scores (fluorescein and lissamine green), ocular clinical signs, Schirmer test, tear breakup time, and global efficacy assessed by the patient and the investigator. Seventeen patients were included. Patient satisfaction improved from $44.5 \pm 19.0$ to $70.2 \pm 19.2 \mathrm{~mm}$ during Thealoz Duo ${ }^{\circledR}$ treatment and from $47.2 \pm 23$ to $57.1 \pm 19.1 \mathrm{~mm}$ during Systane ${ }^{\circledR}$ treatment $(P=0.043$, mixed-effects analysis of covariance). Two secondary efficacy parameters (dry eye symptoms and the impact of their symptoms on work) showed statistically significant advantages for Thealoz Duo ${ }^{\circledR}$ over Systane ${ }^{\circledR}$. There were no statistically significant advantages for Systane ${ }^{\circledR}$ over Thealoz Duo ${ }^{\circledR}$ for any measured parameter. No adverse events were reported. Thealoz Duo ${ }^{\circledR}$ appears to be an effective combination of two active ingredients for the treatment of dry eye and is at least as effective as Systane ${ }^{\circledR}$.
\end{abstract}

Keywords: dry eye, Thealoz Duo ${ }^{\circledR}$, Systane ${ }^{\circledR}$, patients, eyedrop, tears

\section{Introduction}

Once considered merely a deficiency of tears, the understanding of dry eye has developed considerably in recent years, and it is now understood to be a complex illness involving inflammatory processes as well as the physicochemical properties of the tear film. ${ }^{1,2}$ In parallel with this enhanced understanding of the pathophysiology of this common illness have developed improved treatments. In addition, the deleterious effect of eyedrop preservatives on ocular surface is increasingly acknowledged, leading to the development of preservative-free preparations for the treatment of dry eye. ${ }^{3}$

Thealoz Duo $^{\circledR}$ (Laboratoires Théa, Clermont Ferrand, France) is an artificial tear preparation containing two active ingredients: trehalose, a naturally occurring disaccharide of glucose that appears to function in an anhydrobiotic capacity in many organisms, and 
hyaluronate, a widely distributed anionic glycosaminoglycan polysaccharide with biological roles associated with its lubricative and water-retaining properties. Trehalose has been shown not only to stabilize both bilipid membranes and labile proteins against desiccation, but also to have a protective effect against desiccation and oxidative insult in the mammalian eye. ${ }^{4}$ Hyaluronate is a component of many medicinal preparations including those used in cataract surgery, for the treatment of dry eye as well as many commercial skin preparations and antiaging creams. ${ }^{5}$ It is also present in natural human tears. ${ }^{6}$

In the present study, Thealoz Duo ${ }^{\circledR}$ was compared with Systane ${ }^{\circledR}$ (Alcon, Inc., Hünenberg, Switzerland), an artificial tear preparation including hydroxypropyl guar, polyethylene glycol and propylene glycol, and polyquaternium-1 preservative, with particular reference to patient satisfaction.

\section{Methods}

\section{Study design}

The study was a single center randomized, open label, crossover trial. Thealoz Duo ${ }^{\circledR}$ was compared with an active control Systane $^{\circledR}$, an established and effective treatment in dry eye.

The study was approved by the Ethical Committee for Clinical Investigation of Navarre and was conducted according to the Declaration of Helsinki (2008) and Good Clinical Practice (GCP), European directive 93/42/CEE, and in accordance with ISO 14155:2011.

\section{Patients}

Twenty patients were intended to be included with a target of 15 evaluable patients, assuming a $22 \%$ loss. Male or female patients between 18 and 70 years of age with a diagnosis of moderate-to-severe dry eye syndrome (ocular surface disease index [OSDI] score greater than 25) having used tear substitutes in the last 3 months were eligible for inclusion. Patients were also required to be able and willing to give informed consent and to comply with the study protocol.

\section{Exclusion}

Patients with best far corrected visual acuity less than $1 / 10$, severe blepharitis, dry eye secondary to eyelid malposition, corneal dystrophy, ocular neoplasia, filamentous keratitis, corneal neovascularization or orbital radiotherapy, or a history of ocular disease including traumatism, infection, inflammation, allergy, or herpes within the last 3 months were excluded as were patients with a history of inflammatory corneal ulcer or uveitis within the last 12 months. Hypersensitivity to any component of the investigative substances; allergic rhinitis that was current or susceptible to reactivation during the study; or any other medical or surgical history, disorder, or disease that might require modification of ongoing medication during the clinical investigation were grounds for exclusion.

Any ocular treatment including artificial tears during the study was not permitted.

Pregnant or breast-feeding women or fertile women not using an effective means of contraception were excluded.

Administrative exclusions included participation in another clinical study or the exclusion period of another study, previous participation in the current study, and the patient being under guardianship.

Cataract or corneal surgery in the 12 months prior to the study, use of isotretinoin, cyclosporine, tacrolimus, sirolimus, pimecrolimus, and lacrimal plugs in the 3 months prior to the study or use of contact lenses in the 5 to 7 days before the study was not permitted.

\section{Treatment}

Patients were randomized to Thealoz Duo ${ }^{\circledR}$ or Systane ${ }^{\circledR}$. Both treatments were administered as one drop five times daily in both eyes for 7 days followed by a washout period of 5 days, whereupon patients switched to the alternate treatment for 5 days. The two treatments were presented in different $10 \mathrm{~mL}$ bottles. As the bottle design is an integral part of the product conventional treatment, blinding was not possible.

Compliance was recorded on daily diary cards by the patient.

\section{Primary efficacy variable}

Patient satisfaction evaluated by a 0 ("no satisfaction") to 100 ("maximal satisfaction") visual analog scale evaluated on days 0 and 7 of treatment was the predefined primary efficacy variable.

\section{Secondary efficacy variables OSDI}

OSDI was evaluated on days -7 to $-5,0,7,12$, and 19 by using a 12-item questionnaire. Scores ranged from 0 (never) to 4 (always) for each question. A total OSDI ${ }^{\odot}$ (Allergan Inc, Irvine, CA, USA) score with a maximum of 100 was determined. $^{7}$

\section{Dry eye symptoms}

Dry eye symptoms (such as sensations of grittiness, soreness, and sensitivity to light) were recorded by patients using a diary at baseline and midpoint ( 3 days of treatment) and at the end of treatment ( 7 days of treatment). Patients answered questions on the following domains: impact on daily life 
(four questions); impact on daily activities (five questions); emotional impact (six questions); impact on work (four questions); impact on ocular comfort (four questions). A global score for dry eye symptoms was calculated as the sum of the individual components (a total of 20 questions).

\section{Ocular staining (fluorescein test and the lissamine green staining)}

A global ocular staining score was determined from the Oxford 0-5 grading scheme that assesses global ocular staining in corneal area from fluorescein coloration and in temporal and nasal areas from lissamine green coloration in both eyes. Ocular staining was measured during visits at days $0,7,12$, and 19 .

There was one score (on a 0-5 scale) for fluorescein staining and three scores (on a 0-3 scale) for lissamine green staining corresponding to temporal bulbar conjunctiva, corneal area, and nasal bulbar conjunctiva.

\section{Ocular clinical signs}

Palpebral signs including meibomitis and other blepharitis, conjunctival discharge, chemosis, folliculo-papillary conjunctivitis, filamentary keratitis, and other relevant ocular signs were evaluated in each eye at days $0,7,12$, and 19 . Palpebral signs were evaluated on a four-point scale $(0=$ none, $1=$ mild, $2=$ moderate, $3=$ severe) .

The severity of conjunctival hyperemia was scored on a six-point scale using a photographic scale derived from McMonnies and Chapman-Davies. ${ }^{8}$

\section{Schirmer test, tear breakup time}

The Schirmer test was performed, without anesthesia, in each eye at visits on days $0,7,12$, and 19 .

Tear breakup time (TBUT) was determined at baseline and end of treatment.

\section{Global efficacy}

Overall global efficacy was assessed by both patient and investigator at the end of each treatment period. The investigator assessed efficacy on a four-point scale $(0=$ "very satisfactory" to $3=$ "unsatisfactory"). The patient assessed efficacy in the domains of effectiveness (nine questions) and inconvenience (three questions). Every individual question was scored from 0 (greatly disagree) to 3 (greatly agree). The sum of all the individual scores provided the global score of effectiveness and inconvenience.

In addition, at the end of the study, patients completed a questionnaire comprising five questions to compare each treatment.

\section{Statistical methods}

The efficacy analyses were performed on the intent-to-treat sample (those randomized patients who received at least one drop of study medication and who provided at least some data for the primary efficacy variable). The safety analysis was performed on the safety sample (those patients who received at least one drop of study medication).

The primary endpoint was analyzed using a mixed-effects analysis of covariance, considering the patient within the sequence as a random effect and using the type III Sum of Squares for evaluation of the effect.

Other efficacy analyses are presented as descriptive statistics for baseline, under treatment, and change from baseline (when applicable). Comparison between treatments was performed for quantitative criteria using Student's $t$-test for paired samples or a Wilcoxon signed-rank test. A $P$-value less than 0.05 was considered statistically significant.

Adverse event data are presented descriptively.

\section{Results}

\section{Patient disposition}

Seventeen patients were recruited and randomized. Nine received Thealoz Duo ${ }^{\circledR}$ and eight received Systane ${ }^{\circledR}$. All 17 patients were included in the efficacy and safety populations.

\section{Demographics}

Demographics and baseline dry eye parameters are shown in Table 1. Dry eye disease at baseline was moderate in 6/17 (35.3\%) and severe in the remaining 11/17 (64.7\%) patients. Patients with severe dry eye tended to be older than those with moderate illness (53.1 \pm 14.1 vs $42.3 \pm 9.7$ years). The majority of the patients were female (13/17 [76.5\%]). One patient in the Thealoz Duo ${ }^{\circledR}$ group had a dual diagnosis.

Patients treated with Thealoz Duo ${ }^{\circledR}$ and Systane ${ }^{\circledR}$ received $3.7 \pm 0.9$ and $3.5 \pm 0.9$ eyedrops per day. One patient had been prescribed bimatoprost/timolol eyedrops for glaucoma more than 2 years before the commencement of the study and continued to use them throughout the study.

\section{Efficacy}

\section{Primary efficacy variable}

Patient global satisfaction with their treatment improved from $47.2 \pm 23.2$ to $57.1 \pm 19.1 \mathrm{~mm}$ under Systane ${ }^{\circledR}$ treatment and from $44.5 \pm 19.0$ to $70.2 \pm 19.2 \mathrm{~mm}$ under Thealoz Duo ${ }^{\circledR}$ treatment. The difference in the improvement between Systane $^{\circledR}$ and Thealoz Duo ${ }^{\circledR}(13.2 \mathrm{~mm}$ in favor of Thealoz $\left.\operatorname{Duo}^{\circledR}\right)$ was statistically significant $(P=0.043)$ (Table 2). 
Table I Demographics and baseline dry eye characteristics

\begin{tabular}{|c|c|c|c|}
\hline & Thealoz Duo ${ }^{\circledR} /$ Systane $^{\circledR}$ & Systane $^{\otimes} /$ Thealoz Duo $^{\circledR}$ & All patients \\
\hline Patients & 9 & 8 & 17 \\
\hline \multicolumn{4}{|l|}{ Age (years) } \\
\hline Mean \pm SD & $45.3 \pm 11.8$ & $53.8 \pm 14.6$ & $49.3 \pm 13.5$ \\
\hline Median & 43 & 54 & 44 \\
\hline Range & $33-70$ & $33-70$ & $33-70$ \\
\hline \multicolumn{4}{|l|}{ Sex } \\
\hline Male, n (\%) & $3(33.3)$ & $\mathrm{I}(12.5 \%)$ & $4(23.5)$ \\
\hline Female, $\mathrm{n}(\%)$ & $6(66.7)$ & 7 (87.5\%) & $13(76.5)$ \\
\hline \multicolumn{4}{|c|}{ Time from dry eye diagnosis (year) } \\
\hline Mean \pm SD & $4.6 \pm 4.9$ & $1.8 \pm 1.9$ & $3.3 \pm 3.9$ \\
\hline Median & 3.0 & 1.4 & 2.0 \\
\hline Range & $0-13$ & $0-5$ & $0-13$ \\
\hline \multicolumn{4}{|l|}{ Origin of dry eye } \\
\hline Sjogren's syndrome, n (\%) & 0 & 0 & 0 \\
\hline MGD, n (\%) & 0 & 0 & 0 \\
\hline Non-Sjogren's, n (\%) & $8(88.9)$ & $8(100.0)$ & $16(94.1)$ \\
\hline Other, $\mathrm{n}(\%)$ & $2(22.2)$ & 0 & $2(22.2)$ \\
\hline
\end{tabular}

Abbreviation: MGD, Meibomian gland dysfunction.

\section{Secondary efficacy variables \\ OSDI}

OSDI fell during treatment with both Thealoz Duo ${ }^{\circledR}$ and Systane $^{\circledR}$ (Figure 1). The reduction in OSDI was 15.2 \pm 10.9 for Thealoz Duo ${ }^{\circledR}$ and 9.0 \pm 11.9 for Systane ${ }^{\circledR}$. The difference between the treatments was not statistically significant $(P=0.22)$.

\section{Patient-rated dry eye scores}

Patient dry eye symptoms and impact on daily life, daily activities, impact on work, emotional impact, and ocular comfort were broadly similar between the groups at baseline, and all fell during the study (Figure 2). Values for all parameters were lower than baseline by the midpoint assessment and were reduced further by study end. Scores

Table 2 Primary efficacy variable

\begin{tabular}{lll}
\hline & Thealoz Duo $^{\circledR}$ & Systane $^{\circledR}$ \\
\hline VAS at baseline (mm) & & \\
Mean \pm SD & $44.5 \pm 19.0$ & $47.2 \pm 23.2$ \\
Median & 42.0 & 52.0 \\
Range & $12-79$ & $14-94$ \\
VAS under treatment (mm) & & \\
Mean \pm SD & $70.2 \pm 19.2$ & $57.1 \pm 19.1$ \\
Median & 73.0 & 59.0 \\
Range & $14-94$ & $17-87$ \\
Change in VAS (under treatment at baseline) (mm) & \\
Mean \pm SD & $25.7 \pm 25.0$ & $9.9 \pm 26.7$ \\
Median & 23.0 & 8.0 \\
Range & -33 to 76 & -48 to 53 \\
\hline
\end{tabular}

Notes: Patient global satisfaction rated on a $0-100$ visual analog scale at baseline and after 7 days' treatment with Thealoz Duo ${ }^{\circledR}$ or Systane ${ }^{\circledR}$.

Abbreviation: VAS, visual analog scale. were reduced more in the Thealoz Duo ${ }^{\circledR}$ group than in the Systane ${ }^{\circledR}$ group at study end. The difference between the groups achieved statistical significance for dry eye symptoms at the end of treatment and for the impact at work at both midpoint $(-2.1 \pm 1.4 \mathrm{vs}-0.5 \pm 1.2, P=0.004)$ and at the end of treatment $(-2.9 \pm 2.3$ vs $-1.2 \pm 1.8, P=0.010)$. Although the other parameters (impact on daily life, daily activities, work, emotional impact, and ocular comfort) all showed greater reductions (at both midpoint and study end, compared with baseline) on Thealoz Duo ${ }^{\circledR}$ than on Systane ${ }^{\circledR}$ treatment, these differences did not achieve statistical

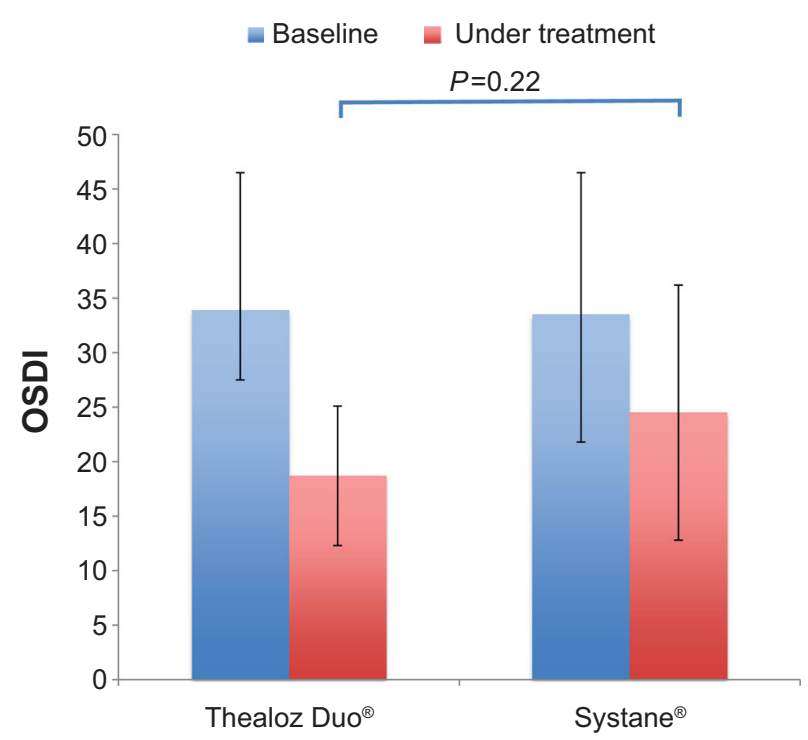

Figure I OSDI scores at baseline and during treatment at baseline and after 7 days' treatment with Thealoz Duo ${ }^{\circledR}$ or Systane ${ }^{\circledR}$.

Note: Values represented are mean $\pm S D$.

Abbreviation: OSDI, ocular surface disease index. 


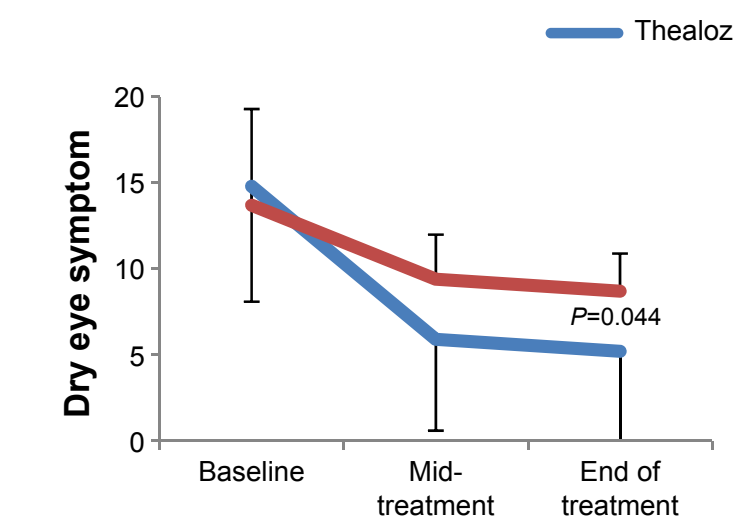

Systane ${ }^{\circledR}$
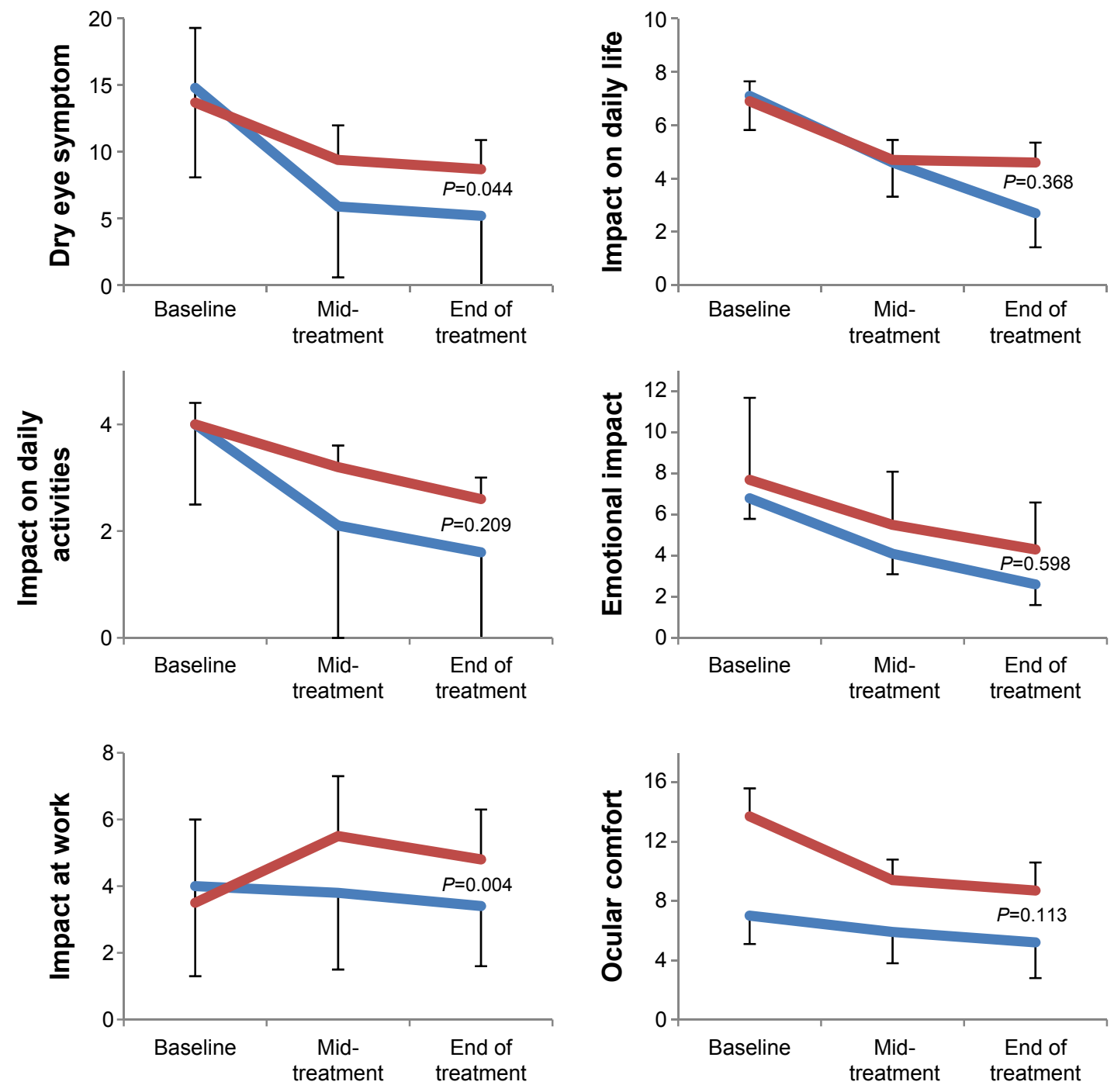

Figure 2 Patient-rated dry eye scores at baseline, after 3 days (midpoint), and 7 days' treatment with Thealoz Duo ${ }^{\circledR}$ or Systane ${ }^{\circledR}$.

Notes: Patients answered four questions on each domain. Values represented are mean \pm SD.

significance. No parameter showed a significant advantage for Systane ${ }^{\circledR}$.

\section{Ocular staining}

Although there were no statistically significant differences between the groups, fluorescein and lissamine green staining improved with both treatments during the study (Figures 3 and 4).

\section{Ocular clinical signs}

No meibomitis or other blepharitis, conjunctival discharge, folliculo-papillary conjunctivitis or filamentary keratitis was reported at baseline or during either treatment.

Chemosis was reported at baseline in several eyes at baseline (all of mild-to-moderate severity) and tended to diminish in both groups during the study (Figure 5). Similarly, conjunctival hyperemia was present in a number of patients at baseline and also tended to diminish during the study (Figure 6).

\section{Schirmer test/TBUT}

The results of the Schirmer and TBUT test both showed a tendency toward improvement during the study without any significant difference between the two treatments.

Global efficacy

Assessed by the patient

The global score for effectiveness was slightly higher for Thealoz $\operatorname{Duo}^{\circledR}(19.9 \pm 4.4)$ than for Systane ${ }^{\circledR}(16.7 \pm 4.1)$, whereas the global score for inconvenience was slightly lower for Thealoz 
Baseline

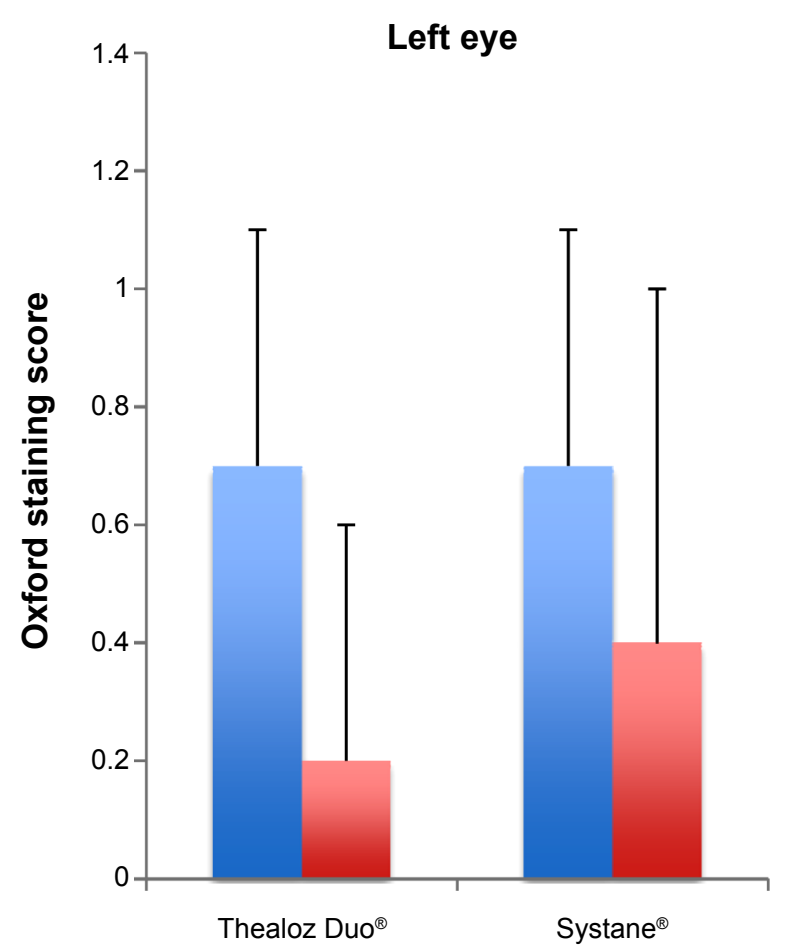

Under treatment

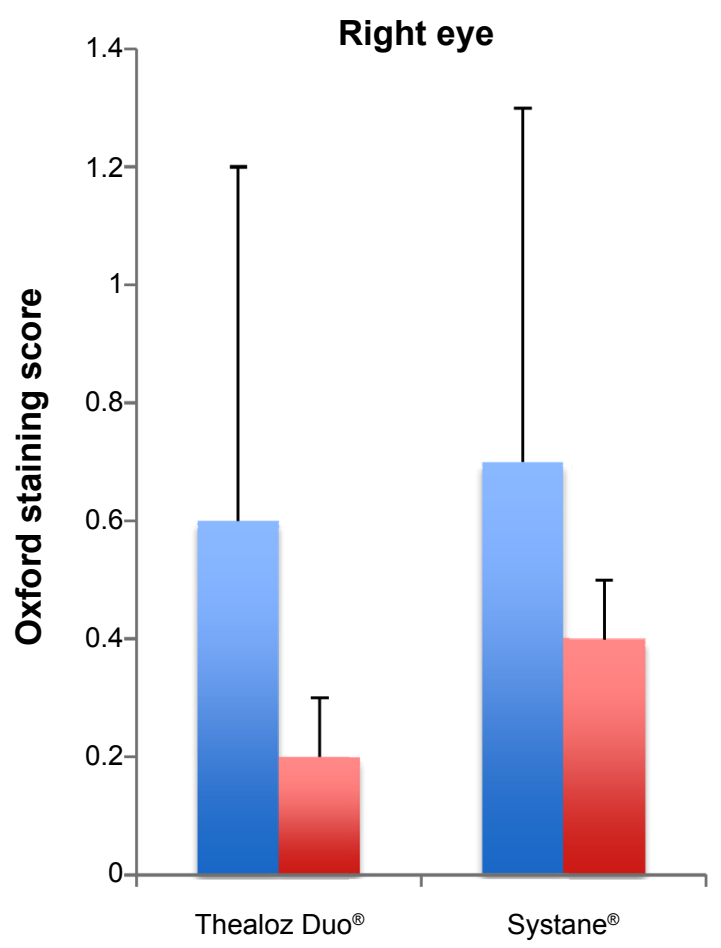

Figure 3 Oxford fluorescein staining scores at baseline and during treatment baseline and after 7 days' treatment with Thealoz Duo ${ }^{\circledR}$ or Systane ${ }^{\circledR}$.

Notes: Differences between treatment groups in the change under treatment were not statistically significant $(P=0.55$ and 0.96$)$ and for the left eye and right eye respectively. Values represented are mean \pm SD.

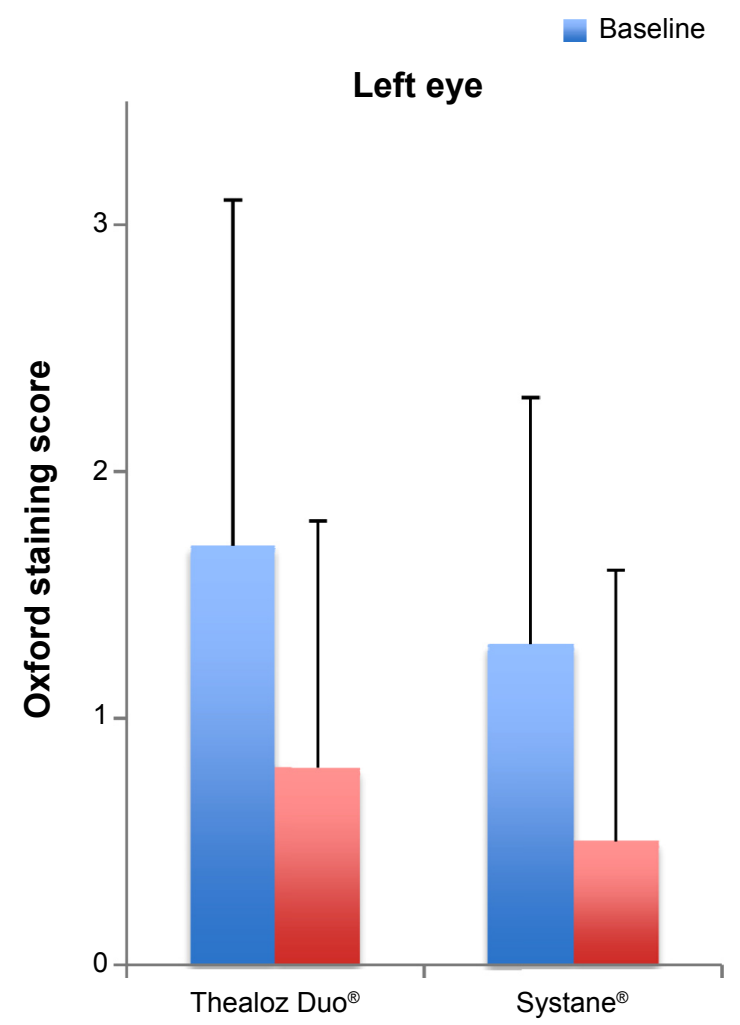

Under treatment

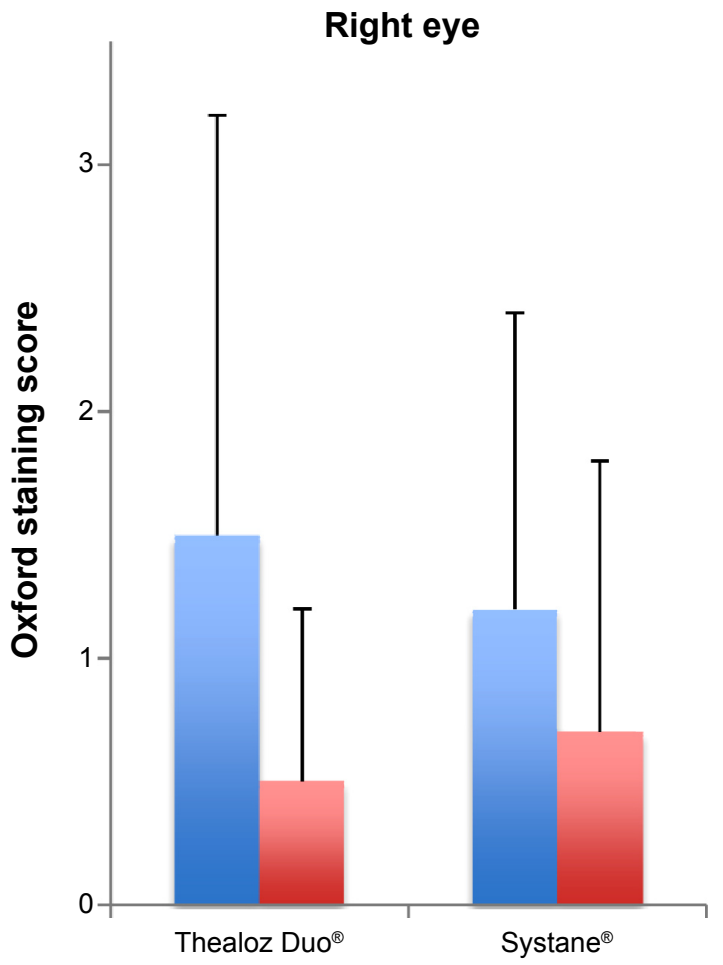

Figure 4 Oxford lissamine green staining scores at baseline and during treatment.

Notes: Differences between treatment groups in the change under treatment were not statistically significant $(P=0.93$ and 0.66$)$ and for the left eye and right eye respectively. 


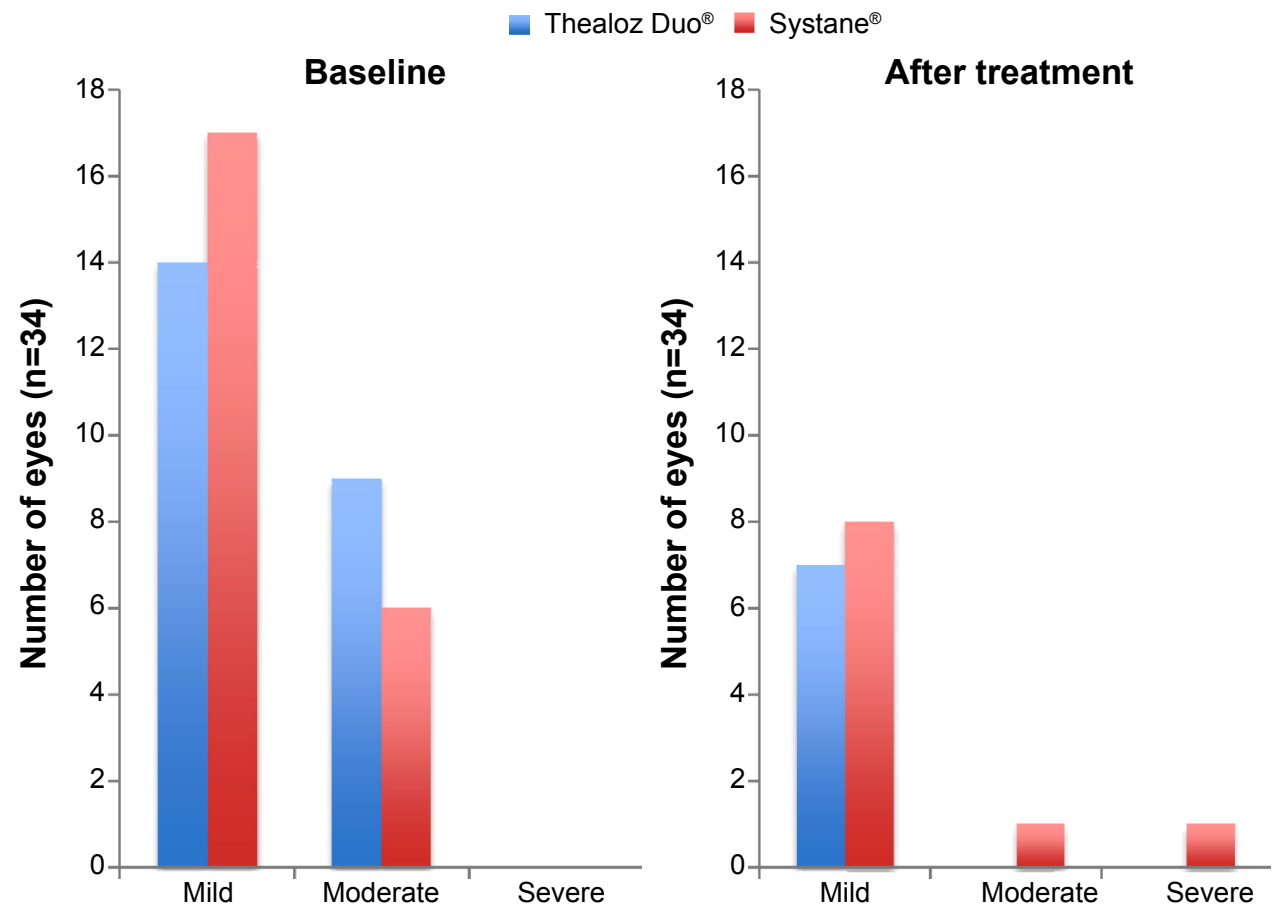

Figure 5 Proportion of patients with chemosis at baseline and after 7 days' treatment with Thealoz Duo ${ }^{\circledR}$ or Systane ${ }^{\circledast}$.

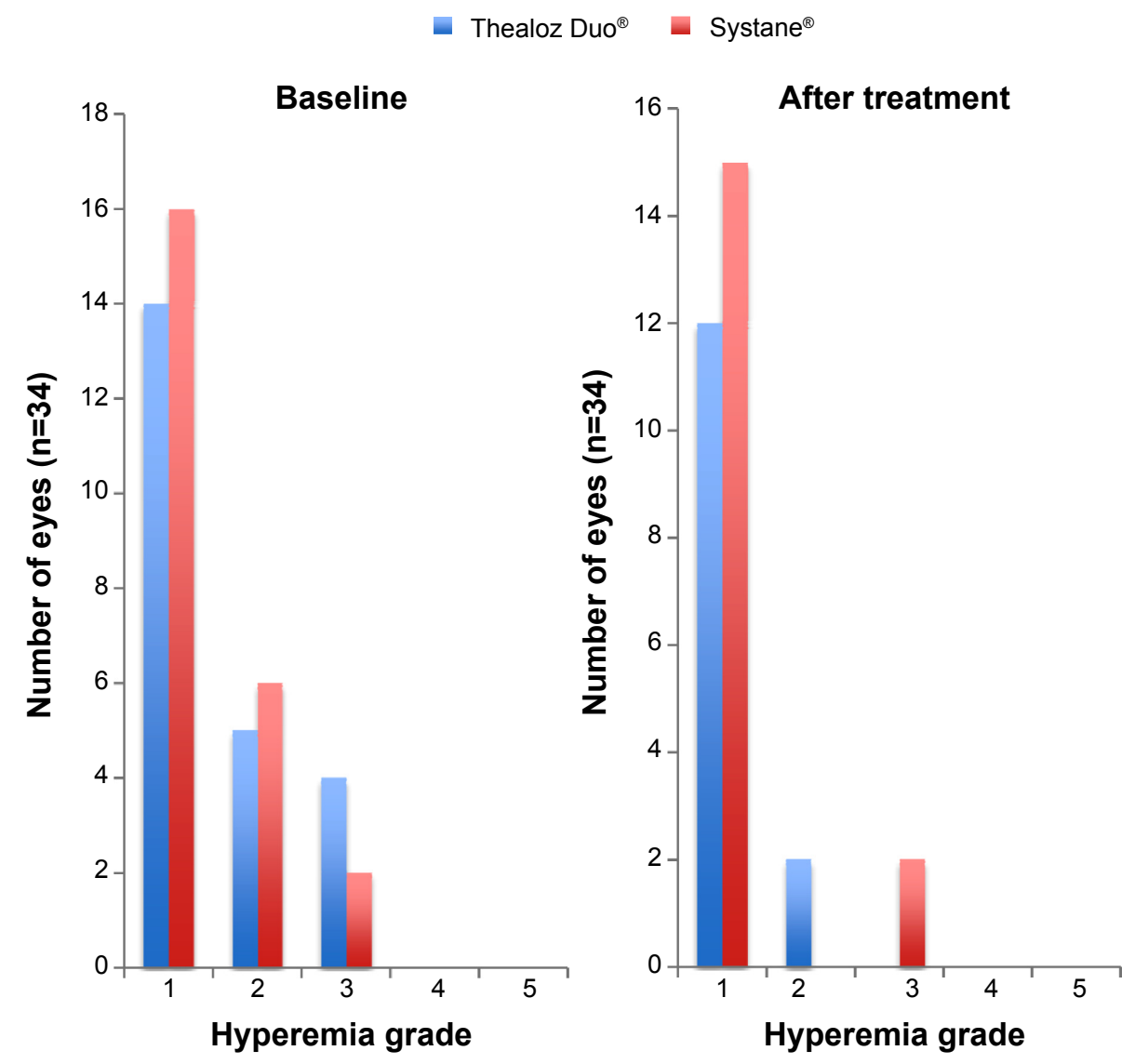

Figure 6 Proportion of patients with conjunctival hyperemia at baseline and after 7 days' treatment with Thealoz Duo ${ }^{\circledR}$ or Systane ${ }^{\circledR}$. Notes: The severity of conjunctival hyperemia rated using a photographic scale derived from McMonnies and Chapman-Davies. ${ }^{8}$ 
$\operatorname{Duo}^{\circledR}(2.4 \pm 1.2)$ than for Systane ${ }^{\circledR}(2.9 \pm 1.1)$. Neither difference was statistically significant.

\section{Assessed by the investigator}

The investigator rated the efficacy of Thealoz Duo ${ }^{\circledR}$ as satisfactory or very satisfactory for 16 patients $(94.1 \%)$, and the efficacy for Systane ${ }^{\circledR}$ as satisfactory or very satisfactory for 14 patients $(82.4 \%)$. Efficacy was reported as not very satisfactory in one patient in the Thealoz Duo ${ }^{\circledR}$ group and three patients in the Systane ${ }^{\circledR}$ group. Unsatisfactory efficacy was not reported in any patient.

\section{Patient preference comparison}

Overall, more patients preferred Thealoz Duo ${ }^{\circledR}$ than Systane ${ }^{\circledR}$ (64.7\% vs $11.8 \%, 23.5 \%$ expressed no preference).

\section{Safety}

No adverse events were reported during the study.

\section{Discussion}

This study indicates that patient satisfaction improved with both Thealoz Duo ${ }^{\circledR}$ and Systane ${ }^{\circledR}$ although Thealoz Duo ${ }^{\circledR}$ resulted in significantly greater improvement in patient satisfaction than did Systane ${ }^{\circledR}$. On secondary efficacy variables, Thealoz Duo ${ }^{\circledR}$ was at least as effective as Systane ${ }^{\circledR}$ on secondary efficacy variables: OSDI, staining, ocular signs, Schirmer/BUT, patient satisfaction/global efficacy (patient and investigator), and patient preference. Moreover, there was a significant advantage for Thealoz Duo ${ }^{\circledR}$ in dry eye symptoms on impact on work. However, this was a relatively small study, and the duration of treatment was relatively short, which likely explains the inconsistency between the results on some parameters. Although some parameters (OSDI, for example) did not show statistically significant differences between the two treatments, the direction of the trends between the treatments was consistent; where statistically significant differences were observed between the treatments, they were all in favor of Thealoz Duo ${ }^{\circledR}$.

Trehalose-containing eyedrops have previously been shown to be effective in in vitro, ${ }^{9,10}$ ex vivo, ${ }^{11}$ and in vivo animal studies ${ }^{12}$ as well as in a few clinical studies. ${ }^{13-15} \mathrm{~A}$ further advantage of this formulation is a longer residency time than hyaluronate alone, as recently shown in a randomized, double-masked study. ${ }^{16}$ Clinical studies have investigated the use of trehalose in eyedrops with positive results. These larger studies established significant benefits of trehalosecontaining eyedrops over saline and hydroxymethylcellulose eyedrops. ${ }^{13,14}$ The utility of hyaluronate-containing eyedrops is well established in the treatment of dry eye. ${ }^{17-22}$
This first study of eyedrops containing both trehalose and hyaluronate shows that they are at least as effective as commonly used Systane ${ }^{\circledR}$ eyedrops and, on some parameters, are more effective. Future studies in larger patient populations are awaited with interest.

\section{Acknowledgments}

The study was sponsored by Laboratoires Théa. The manuscript was prepared with the assistance of Dr JF Stolz, who was remunerated by Laboratoires Théa.

\section{Disclosure}

The authors report no conflicts of interest in this work.

\section{References}

1. Baudouin C. Un nouveau schema pour mieux comprendre les maladies de la surface oculaire. [A new approach for better comprehension of diseases of the ocular surface]. J Fr Ophtalmol. 2007;30(3):239-246. French.

2. Bron AJ, Tomlinson A, Foulks GN, et al. Rethinking dry eye disease: a perspective on clinical implications. Ocul Surf. 2014; 12(2 Suppl):S1-S31.

3. Baudouin C, Labbé A, Liang H, Pauly A, Brignole-Baudouin F. Preservatives in eyedrops: the good, the bad and the ugly. Prog Retin Eye Res. 2010;29(4):312-334.

4. Luyckx J, Baudouin C. Trehalose: an intriguing disaccharide with potential for medical application in ophthalmology. Clin Ophthalmol. 2011;5:577-581.

5. Rah MJ. A review of hyaluronan and its ophthalmic applications. Optometry. 2011;82(1):38-43.

6. Frescura M, Berry M, Corfield A, et al. Evidence of hyaluronan in human tears and secretions of conjunctival cultures. Biochem Soc Trans. 1994;22(2):228S.

7. Schiffman RM, Christianson MD, Jacobsen G, Hirsch JD, Reis BL. Reliability and validity of the Ocular Surface Disease Index. Arch Ophthalmol. 2000;118(5):615-621.

8. McMonnies CW, Chapman-Davies A. Assessment of conjunctival hyperemia in contact lens wearers. Part I. Am J Optom Physiol Opt. 1987;64(4):246-250.

9. Chen W, Zhang X, Liu M, et al. Trehalose protects against ocular surface disorders in experimental murine dry eye through suppression of apoptosis. Exp Eye Res. 2009;89(3):311-318.

10. Matsuo T. Trehalose protects corneal epithelial cells from death by drying. Br J Ophthalmol. 2001;85(5):610-612.

11. Hovakimyan M, Ramoth T, Löbler M, et al. Evaluation of protective effects of trehalose on desiccation of epithelial cells in three dimensional reconstructed human corneal epithelium. Curr Eye Res. 2012; 37(11):982-989.

12. Li J, Roubeix C, Wang Y, et al. Therapeutic efficacy of trehalose eye drops for treatment of murine dry eye induced by an intelligently controlled environmental system. Mol Vis. 2012;18:317-329.

13. Matsuo T, Tsuchida Y, Morimoto N. Trehalose eye drops in the treatment of dry eye syndrome. Ophthalmology. 2002;109(11):2024-2029.

14. Matsuo T. Trehalose versus hyaluronan or cellulose in eyedrops for the treatment of dry eye. Jpn J Ophthalmol. 2004;48(4):321-327.

15. Ramoth T, Hovakimyan M, Guthoff RF, Stachs O. Charakterisierung der ranenfilmdynamik am Beispiel einer Trehaloseapplikation zur Behandlung des Trockenen Auges. [Characterisation of tear film dynamics after application of trehalose for treatment of dry eye]. Klin Monbl Augenheilkd. 2013;230(12):1220-1224. German.

16. Schmidl D, Napora KJ, Werkmeister RM, Rosner P, Garhofer G, Schmetterer L. Effect of lachrymal substitutes on tear film thickness in patients with moderate dry eye syndrome. Poster A0184 Presented at: ARVO 2014 Annual Meeting. 
17. Cheema A, Aziz T, Mirza SA, Siddiqi A, Maheshwary N, Khan MA. Sodium hyaluronate eye drops in the treatment of dry eye disease: an open label, uncontrolled, multi-centre trial. J Ayub Med Coll Abbottabad. 2012;24(3-4):14-16.

18. Baeyens V, Bron A, Baudouin C; Vismed/Hylovis Study Group. Efficacy of $0.18 \%$ hypotonic sodium hyaluronate ophthalmic solution in the treatment of signs and symptoms of dry eye disease. J Fr Ophtalmol. 2012;35(6):412-419.

19. Baudouin C, Cochener B, Pisella PJ, et al. Randomized, phase III study comparing osmoprotective carboxymethylcellulose with sodium hyaluronate in dry eye disease. Eur J Ophthalmol. 2012;22(5): 751-761.
20. Lee JH, Ahn HS, Kim EK, Kim TI. Efficacy of sodium hyaluronate and carboxymethylcellulose in treating mild to moderate dry eye disease. Cornea. 2011;30(2):175-179.

21. Vogel R, Crockett RS, Oden N, Laliberte TW, Molina L; Sodium Hyaluronate Ophthalmic Solution Study Group. Demonstration of efficacy in the treatment of dry eye disease with $0.18 \%$ sodium hyaluronate ophthalmic solution (vismed, rejena). Am J Ophthalmol. 2010;149(4):594-601.

22. Prabhasawat P, Tesavibul N, Kasetsuwan N. Performance profile of sodium hyaluronate in patients with lipid tear deficiency: randomised, double-blind, controlled, exploratory study. Br J Ophthalmol. 2007;91(1):47-50.

\section{Publish your work in this journal}

Therapeutics and Clinical Risk Management is an international, peerreviewed journal of clinical therapeutics and risk management, focusing on concise rapid reporting of clinical studies in all therapeutic areas outcomes, safety, and programs for the effective, safe, and sustained use of medicines. This journal is indexed on PubMed Central, CAS,
EMBase, Scopus and the Elsevier Bibliographic databases. The manuscript management system is completely online and includes a very quick and fair peer-review system, which is all easy to use. Visit http://www.dovepress.com/testimonials.php to read real quotes from published authors.

Submit your manuscript here: http://www.dovepress.com/therapeutics-and-clinical-risk-management-journal 